\title{
Del martillo y el escoplo a la máquina de machihembrar. La industria del mueble en España en el siglo XIX
}

\author{
Sofía Rodriguez Bernis *
}

RESUMEN

La España del siglo xix se incorpora tardiamente a los mercados europeos de las artes industriales. Este articulc examina el esfuerzo realizado, en el campo de la fabricación de mobiliario doméstico, para revitalizar la producción: la implantación de los procedimientos mecánicos de fabricación, la definición de nuevos criterios estéticos que aplicar al diseño de los nuevos objetos decorativos, y la adecuación de la formación de los trabajadores y de la organización del trabajo al proceso industrial.

\section{ABSTRACT}

During the 19th Century Spain arrives late to the developement of the Industiral Arts. This paper is focused on explaining the efforts carried out by schollars and workshops to improve the production in the field of domestic furniture. These effors called for: the settlement of mechanical procedures, the search of the new aesthetical patterns for the new decorative objects, and the fitting of workers' skills and working structures to the spreading of the machine.

«Al lado de productos de verdadero merecimiento, han venido algunos objetos que demuestran una candidez, una inocencia industrial verdaderamente lastimosa..., que hay quien presenta objetos menudos cuyo volumen no llega a un metro cuadrado, acompañados de una instalación que consiste en un robusto armario, para el cual se ha necesitado un pinar, cuyo transporte casi ha exigido un wagon, cuya rudeza de formas no tiene par, y cuyos ornatos consisten en una mano de pintura de brocha gorda" '. Esta des-

* Conservadora. Museo Nacional de Arte Decorativas.

FERNÁNDEZ DE LOS RIOS, A., La exposición universal de 1878. Guía-itinerario, Madrid, 1878, pág. 293. 
piadada crítica de Fernández de los Ríos al armario presentado por Francisco Pons, mueblista balear, en la sección española de la Exposición Universal de París de 1878, pone de manifiesto la desoladora situación a la que había conducido la práctica rutinaria del oficio en los talleres nacionales, a la que solo se sustraían contadas excepciones. España no había sabido responder a las nuevas exigencias planteadas por la fabricación y distribución de bienes de consumo, que habían impulsado la carrera que todos los países de Europa emprendieran para la conquista de un mercado en expansión, mercado que exigía productos de buena calidad a un precio razonable. Esta debilidad estructural permitió que el mobiliario extranjero, francés e inglés principalmente, invadiera las casas españolas que disfrutaban de una cierta holgura económica, en tanto que los fabricantes españoles surtían al público de objetos que, en la mayor parte de los casos, seguian las modas extranjeras sin reparos ni imaginación. A este estado de cosas hay que añadir las rémoras de una tardía e incompleta mecanización de las pequeñas industrias dedicadas a la fabricación de equipamiento doméstico, los precios excesivos de las fuentes de energía, y una política arancelaria y fiscal anárquica.

Para transformar esta poco halagüeña realidad se fueron sucediendo tentativas de reforma de carácter teórico y práctico, poco sistemáticas hasta mediados de siglo, con las que se trató de revitalizar a las artes industriales. Se pueden concretar en tres categorías: la implantación de los modernos procedimientos mecánicos de fabricación, la definición de nuevos criterios estéticos que aplicar a la producción de objetos industriales, y la adecuación de la formación de los trabajadores y de la organización del trabajo al proceso industrial.

\section{LA MECANIZACIÓN}

Hasta bien avanzado el siglo xIX el mobiliario se fabrica con las técnicas y utillajes tradicionales, y por los artesanos formados en el seno de la organización gremial, disuelta solo en 1838, que determinaba rígidamente las especialidades del oficio de la madera -carpinteros, ebanistas, silleros...-, y que dotaba al trabajador de destrezas ajenas a la mecanización de los talleres que la industrialización iba a imponer inexorablemente.

Poco a poco algunos artesanos se arriesgarán a comprar alguna máquina-herramienta para avivar su ritmo de trabajo y servir a una clientela en aumento. Los más afortunados irán pasando de ser empresas familiares con clientela local a poseer fábricas de ámbito nacional. El cambio fué dificultoso y el ritmo de desarrollo lento, y no se alcanzaron cotas en la dotación de infraestructuras y en la producción en algo semejantes a las 
europeas hasta los años ochenta; si en Inglaterra y Francia, por no citar más que dos ejemplos significativos, se da el gran paso de la mecanización de las industrias llamadas "artísticas" entre los años cuarenta y los sesenta, en España habrá que esperar a esta última década para encontrar noticias del empleo tímido de máquinas-utensilio movidas a mano o a motor en carpinterías y ebanisterías, máquinas cuya implantación no se puede afirmar que sea sistemática más que en los últimos veinte años de la centuria.

En el siglo $x \mid x$ los utensilios de carpinteria se mueven gracias a motores de vapor e hidráulicos. Antes de exponer cómo y cuándo se implantaron en España, conviene recordar brevemente la cronología de su uso en Europa. Los motores de vapor se difunden sobre todo a partir de 1836, y la modalidad que se considera más fiable, la de émbolo horizontal, se presenta en la Exposición Universal de 1855. Será esta variante la que predomine en el viejo continente hasta fines del siglo $x \mid x$. Los motores hidráulicos inician su expansión en esta misma exposición, aunque nunca llegaron a gozar del favor de los anteriores. Los eléctricos se popularizaron a raíz de las demostraciones aplicadas a las máquinas-herramienta en la exposición de Viena de 1873.

Siguiendo la tónica general, los motores de vapor dominan la industria española, y se dan algunos intentos, tímidos, de implantar los hidráulicos ${ }^{2}$. Hay que esperar al siglo xx para encontrar maquinaria eléctrica en los talleres de carpintería y ebanistería ${ }^{3}$. Esta maquinaria es, en su mayor parte, de importación, y procede de Inglaterra, Alemania y Bélgica. Sirvan como ejemplo dos iniciativas pioneras, destinadas a obtener madera cortada en grandes cantidades utilizando sierras horizontales: la de la Serrería de los Reales Montes de Valsaín, en la que se instaló una, sistema Corliss, de Bélgica, y la del empresario Gregorio Oviés, que dotó a su fábrica de otra, sistema Otto, alemana. Estas últimas fueron muy abundantes.

Las contribuciones españolas a la fabricación de maquinaria son limitadas, y vienen, en general, de Barcelona: la firma Hermanos Alexander,

Sobre la industrialización española vid. el excelente libro de Gonzalo MENÉnDEz PIDAL, La España del siglo xix vista por sus contemporáneos, Centro de Estudios Constitucionales, Madrid, 1989.

Gumersindo VICuÑa, en un artículo publicado en La semana industrial titulado "La gran industria y la industria doméstica" propone el aprovechamiento de los saltos de agua del Guadarrama para alimentar acumuladores cuya energía fuera enviada a la capital por cable, de tal manera que los pequeños talleres pudieran abaratar los costes de energía, instalando motores eléctricos de poca potencia. 
que construía máquinas horizontales de diversas potencias, y que consiguió una Medalla de Oro en la Universal de París de 1878, y otra en la de Barcelona de 1888, representa una iniciativa que no se prodigó demasiado.

En cuanto a los motores hidráulicos, su presencia fué mucho más modesta: solo algún industrial como José Amorós Vidal, de Zaragoza, que se anuncia desde 1882 en La semana industrial, los suministra de diferentes tamaños y aplicaciones, entre ellos algunos destinados a máquinas para aserrar madera. El balance que presenta esta firma en 1898 no resulta espectacular: ha instalado 25 unidades cada año, de modo que en esta fecha se enorgullece de contar con 275 en funcionamiento, en establecimientos de todo género.
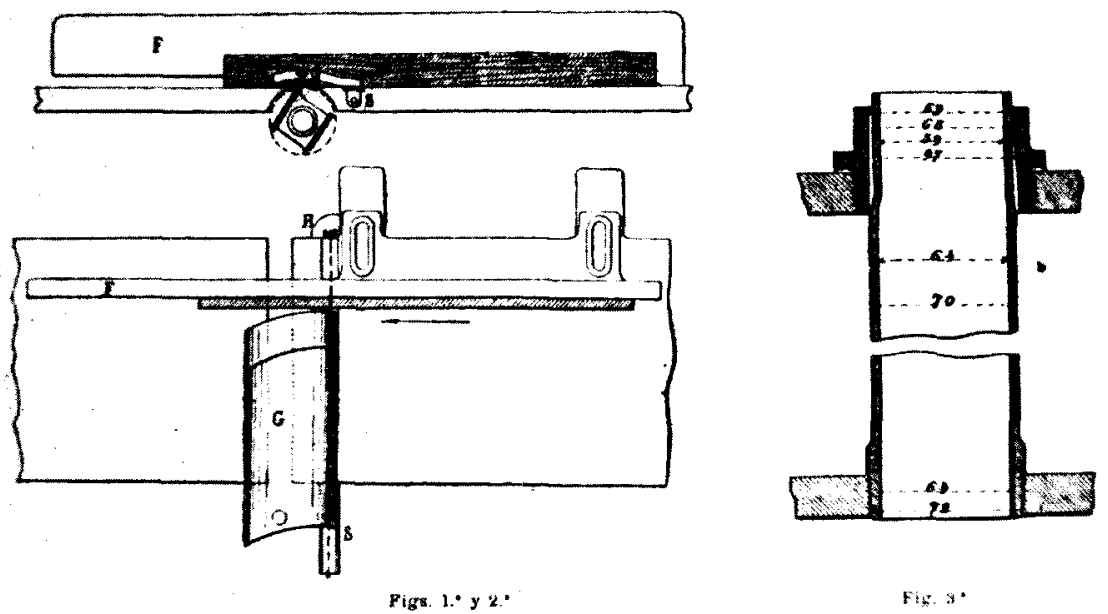

Figura 1. Máquina de cepillar. La semana industrial, 1886.

La razón de que los fabricantes españoles se muestren remisos a la modernización de su equipamiento es sencilla: las máquinas resultan aún excesivamente caras, debido a los gastos arancelarios y de transporte generados por la importación en unos casos, y en otros, cuando los aparatos son de fabricación nacional, a la la necesidad de efectuar inversiones considerables con el fruto de la venta de un número modesto de unidades. Por otra parte, la fuerza motriz es costosa: las máquinas de vapor son de alto consumo, las de gas ruidosas y molestas; las tarifas de la Compañía del Gas son abusivas y, en lo que respecta al agua necesaria para los motores hidráulicos, los suministradores, como por ejemplo el Canal de Isabel II en Madrid, no la procuran con la presión y regularidad necesarias, 
al tiempo que ponen inconvenientes para otorgar licencias que permitan su aplicación industrial. A esto hay que añadir los tributos que gravan el consumo de materias primas, las limitaciones impuestas en las grandes ciudades para instalar industrias mecanizadas en los barrios céntricos, los recargos de la propiedad urbana, y otros impedimentos de este género que se acusaron más en Madrid que en Barcelona o Bilbao.

Los motores de los que hemos hablado se aplican a máquinas-herramienta para carpintería y ebanistería: sierras de bastidor, de cinta o circulares, cepillos, máquinas mortajadoras o de machihembrar, reengruesadoras, de moldurar, de taracear o calar maderas para marquetería, y de tornear. También la mayor parte son importadas y caras. En España se construyen a partir de la década de los ochenta en ciudades como Barcelona, Valencia, Zaragoza, Madrid y Sevilla, pero únicamente para abastecer a la Península y a las Colonias, ya que dependen de patentes extranjeras. Cabe citar el Centro Industrial Mecánico, que producia sierras de movimiento alterno, de cinta y circulares, máquinas de cepillar, de hacer molduras, de escoplear y de ensamblar; y la firma Escuder y Castellá, de Barcelona, que en la última década del siglo ofrece máquinas de hacer molduras a 550 pesetas, de cepillar a 45 , y de reengruesar a 100. Rarísimas veces se introducen mejoras en to ya inventado fuera, y cuando así sucede son casi insignificantes, como una barrena para labrado mecánico de barras correderas para mesas colisas de comedor de un tal Francisco Andrés, de Valencia (1882), o el sistema automático para mesas extensibles de un mueblista relativamente modesto de Logroño, de nombre Ramón Toledo.

Una mecanización, pues, difícil y costosa, que es causa de que sean pocos los talleres de carpintería donde se sierre o se abran cajeados para ensamblajes empleando otros procedimientos que no sean «los utilizados por los egipcios, que ya conocian la sierra, el escoplo y el mazo" ${ }^{4}$, en palabras del ingeniero Gironi, uno de los adalides de la industrialización, vertidas en un artículo de La semana industrial, en 1882. Es en estas fechas, sin embargo, cuando se puede empezar a hablar de talleres mecanizados de una cierta envergadura, con un mayor número de obreros - generalmente entre cincuenta y ciento cincuenta - y con una división del trabajo moderna. Así, Barcelona, Valencia, el País Vasco y Madrid podrán acometer la fabricación de una gama de productos que, por vez primera, rebasa el corto cupo tradicional. Grandes talleres de aserrío pondrán a disposición de los carpinteros cantidades suficientes de madera de

4 Enero, pág. 21. 
sierra ${ }^{5}, y$ aparecerán firmas que serán capaces de diseñar y producir proyectos decorativos completos y muebles «listos para llevar» para cada una de las estancias habituales de una casa corriente: dormitorios, despachos, salones y comedores, principalmente. Un buen ejemplo de lo que fueron estas fábricas, que con frecuencia contaban con una tienda abierta al público, es Herederos de Manuel Urola, fundada en 1825 en Tolosa, y trasladada en 1865 a San Sebastián: en 1898 contaba con ciento cincuenta trabajadores, que se distribuian en dos talleres, uno mecánico para las labores generales, movido por motores de vapor de veinte y cincuenta caballos, y otro manual para acabados. De alli salía todo tipo de muebles y, además, molduras decorativas y parquets.

Con la industrialización llegaron otro tipo de novedades como los llamados "muebles de Viena» o «muebles de madera curvada», hoy conocidos bajo el nombre genérico de su más destacado fabricante, Thonet. La central vienesa de esta empresa otorgó la representación de sus creaciones a Thonet Hermanos, de Madrid, y sus modelos fueron copiados por fábricas locales, de las que las más conocidas son las valencianas de Luis Suay Bonora y de Salvador Albarcar y Gil. Esta última estaba equipada con máquinas de vapor a cuyo servicio operaban doscientos obreros, cantidad considerada entonces muy elevada. Como de costumbre, estas factorías también restringian su mercado a la Península y a las Colonias.

La mecanización trajo consigo cambios fundamentales en las técnicas constructivas y en la apariencia del mobiliario. Los cortes de la madera son más duros y precisos y las secciones menos robustas que las corrientes en el mobiliario artesanal. Los ensamblajes se simplifican para facilitar el armado rápido y en cadena, y a veces se hacen en vivo en zonas no estructurales, en las que los paneles ocasionalmente se reciben por simple apoyo en los montantes y largueros de la carcasa. En estos casos la sujección se realiza con molduras que se clavetean al perímetro de todos los miembros. La fabricación en serie impone la preparación previa de todas las piezas por separado, incluído el chapeado, antes del ensamblaje final, todo lo contrario que en la práctica tradicional de la marquetería; las molduras se aplican después para disimular las bruscas transicio-

\footnotetext{
Cabe citar la serrería inaugurada en 1884 por el Cuerpo de Ingenieros de Montes de Valsain. Estaba asistida por motores de vapor belgas y máquinas-herramienta inglesas, y contaba con una sola sierra de fabricación española, pequeña. Este establecimiento generaba madera de sierra destinada casi únicamente a los talleres de Madrid, a la vez que productos acabados para carpintería doméstica, como cornisas, zócalos, jambas, pilastras, molduras, bastones para cortinas y pasamanos. Vid. Exposición universal de Barcelona, 1888. Catálogo razonado de los objetos expuestos por el Cuerpo de Ingenieros de Montes, Madrid, 1888.
} 
nes entre montantes, largueros y paneles. De ahi resultan muebles recargados de perfiles, que no solo tienen una función decorativa sino que se justifican merced a razones de estabilidad y solidez. Las ornamentaciones a máquina están menos matizadas y se resuelven en menos planos que las tradicionales, sobre todo desde que fueron posibles las molduras grabadas en relieve y los estampados en caliente, a fuego y a presión ${ }^{6}$.

La marquetería se abarata gracias a las sierras para chapeados finos, y a las llamadas de taracear o calar madera: en la Exposición Universal de Barcelona de 1888 todavía causaron asombro las máquinas destinadas a este menester que se exhibian en la Galeria anular o del trabajo; poco después algunos industriales las fabrican en España, como la Viuda de Soler, desde 1897; un poco antes, en Madrid, la prensa especializada comenta como novedad un sistema inglés consistente en hojas de maderas finas de solo un cuarto de milímetro que se importaban ya aplicadas sobre estructuras de pino, y que fué copiado por ciertos talleres de la calle de Ayala.

En España, incluso en los últimos veinte años del siglo, siguió siendo frecuente que la construcción de los muebles fuera mixta, y que los fabricados a máquina estuvieran acabados a mano.

\section{LA DEFINICIÓN DE NUEVOS CRITERIOS ESTÉTICOS}

La inercia que guía la práctica laboral comienza a resquebrajarse en los años treinta, década de cambio de gustos y de novedades parciales. Como señala en 1836 un autor anónimo en el Seminario pintoresco espa$\tilde{n o l}$, en pocos años se había pasado "de los sillones de baqueta de Moscovia (a) el almacén de la calle Hortaleza" ', establecimiento que puede considerarse como la primera tienda moderna en su género ${ }^{8}$, con una oferta de tipos de muebles y de modos decorativos más variada de lo que era costumbre, dado que reunía productos de diferentes fabricantes. Mesonero Romanos, por los mismos años, comenta la variedad y el buen gusto que comienzan a apreciarse en los muebles, a la vez que elogia el buen hacer de los ebanistas madrileños, por la precisión de los ensam-

\footnotetext{
- Por ejemplo, las molduras de las fábricas Pujadas y Compañía, de Barcelona, y Francisco Guilleumas, de la misma ciudad.

Semanario pintoresco español, Madrid, 1836, pág. 56.

- La Perfumería Diana, la primera tienda a la moda de París, con escaparates, anaquelerías y otros accesorios, se abrió en 1835 en la calle Caballero de Gracia. De estilo similar fueron los almacenes de la calle Hortaleza.
} 
blajes y los cuidados acabados ${ }^{9}$. A partir ahora la clientela que puede amueblar su casa a la moda se amplía. Los ojos de los que definen el buen gusto se vuelven hacia Europa, sobre todo hacia Francia, cuyos productos se importan y se imitan. No se desarrollan criterios formales y decorativos originales, y se adoptan acríticamente los historicismos europeos, que se van superponiendo a la tradición decorativa fernandina que sobrevive hasta mediados de siglo. Los talleres comienzan poco a poco a mecanizarse, y requieren modelos adecuados a las nuevas formas de fabricación.

A partir de entonces, con más timidez que en Europa y, en general, con menor audacia ideológica, los profesionales e intelectuales comienzan a dedicar sus esfuerzos a definir criterios estéticos con que salir de la situación de indefinición y de dependencia que se padecía. Ingenieros como Gironi o Vicuña, arquitectos y ornamentistas como Rigalt, escritores e intelectuales como Fernandez de los Ríos y Emilia Pardo Bazán, y eruditos y conocedores como Mariátegui o Miquel i Badía aportaron desde simples opiniones hasta propuestas sistematizadas para tal fin. Se tiene la convicción de que de este modo se fomentará el desarrollo de una industria propia con valores estéticos originales, y se contribuirá a evitar que fabricantes no españoles acaparen el mercado nacional. Se trata, además, de dar las pautas para determinar qué apariencia habrán de tener los objetos fabricados con métodos industriales.

Como señala Nuria Dalmases ${ }^{10}$ España se hace eco de las cuestiones planteadas a escala europea a raíz de la Exposición Internacional de 1851 , relativas a la relación entre el arte y la industria, entre los modelos estéticos históricos y los avances mecánicos, entre la calidad y la producción masificada. Las aportaciones de los españoles al debate internacional son muy moderadas. Las más progresistas tratan de establecer de una relación racional y equilibrada entre los materiales a emplear, el modo de construcción y las formas de los objetos. Se trata de integrar la forma y la función, de manera que "lo útil» y "lo bello", es decir, la estructura y la ornamentación, se adecúen a los valores de uso de cada mueble, y que este uso sea la razón integradora de ambos extremos.

El representante más destacado de esta actitud es el catalán Rigalt que dedicó sus esfuerzos a definir los conceptos de lo útil y lo bello aplicados a las artes industriales, y a establecer los principios que rigieran su

\footnotetext{
9 Mesonero Romanos, R., Descripción de la Corte y Villa. Manual de Madrid, Madrid, 1831, pág. 257.

10 "El "Album" de Rigalt", El Diseño en España. Antecedentes históricos y realidad actual. Ministerio de Industria y Energia. ADGFAD. ADIFAD. ADAP. BCD. 1985, pág. 110.
} 
traducción en la práctica. Para ello, partiendo del conocimiento preciso y completo de las técnicas propias de los diversos oficios, dedica parte de sus publicaciones a procurar un repertorio de modelos formales de objetos - diseños para carpintería, ebanistería, rejería, etc- apropiados para ser fabricados en talleres mecanizados. Los libros de Rigalt ", que se declara expresamente partidario de la maquinización, se dirigen a los profesionales, para auxiliarles en la adaptación de sus conocimientos a los avances que llegan de más allá de los Pirineos. Propone, además, métodos puestos al día para la formación de obreros y artesanos, y normas para la organización eficaz del trabajo.

Rigalt plantea su concepción de la forma y la función desde un punto de vista esencialmente técnico y práctico: entiende por utilidad el fin y el uso de cualquier objeto, la manera de adecuarse al lugar de colocación al

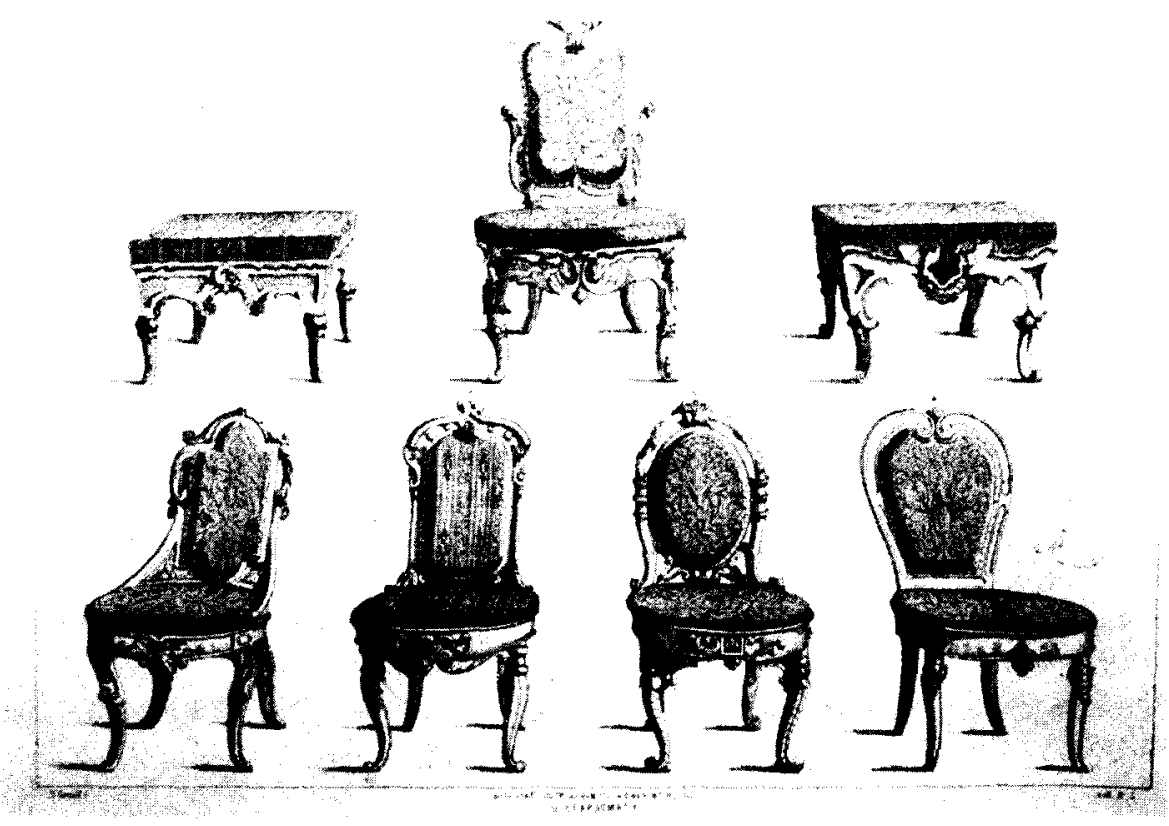

Figura 2. RIGALT, Album enciclopédico pintoresco de las Artes Industriales, 1857. Sillas de estilo "decadente" o "churrigueresco".

La fundamental es el Album enciclopédico-pintoresco de las artes industriales, Barcelona, 1857. Publicó asímismo Cartapacios gráficos de dibujo. Geometría. Modelos, s.l., s.f., Cartapacios de dibujo para uso de las escuelas de instrucción primaria, Barcelona, 1863, y un Album gráfico de las artes y los oficios, Barcelona, 1884. 
que esté destinado, y su resistencia al deterioro; la belleza solo se alcanza por la vía del conocimiento de las obras de arte del pasado, que se han de juzgar con criterios selectivos. Unicamente acepta los modelos historicistas de sobria estructura y escasa o nula decoración supérflua, que se puedan adaptar fácilmente a la fabricación industrial y a los usos y costumbres contemporáneos. Propone una sencilla división de los estilos históricos, que resume en cuatro: "arte antiguo», "arte ojival», "renacimiento", y "arte decadente, restaurado, reformado o moderno", al que asímismo llama "churrigueresco" ${ }^{12}$. Cualquiera de los tres primeros puede tomarse como modelo; el último se proscribe. El autor publicó varios repertorios de dibujos para mostrar con claridad sus asertos, y para que sirvieran de pauta a los fabricantes. En general las fuentes históricas que maneja son bastante eclécticas, a pesar de su expresa intención de ser lo más riguroso posible: los objetos de ascendencia clásica y renacentista están contaminados de componentes del Primer Imperio y muestran elementos del Renacimiento francés pasado por la imaginación decimonónica; los ojivales son deudores del neogótico parisino y, excepcionalmente, de algún modelo próximo a Pugin. El "churrigueresco", por lo que se puede observar en las láminas que ilustran el Album enciclopédico-pintoresco de las Artes Industriales (Barcelona, 1857), es un compendio de ornamentaciones próximas a los "luises" franceses en su versión más opulenta, y de otras procedentes del último barroco español. Por otra parte, se adivina una cierta intención de buscar fuentes geográficamente próximas $y$, por tanto, más familiares al gusto general.

De la armonización de utilidad y belleza surgen las formas que cada oficio plasmará con diferentes materiales y técnicas. La "honradez de los materiales", por emplear una expresión francesa muy en boga entonces, está en la base de todo proceso artesanal o industrial: la naturaleza de los mismos, su composición y comportamiento, determinan la forma que habrán de adoptar. "Todo ha de salir de la idea general de la obra, sin esfuerzo alguno; y sobre todo nada debe estar aplicado inoportunamente" ${ }^{13}$. En el caso del mobiliario, la madera ha de ser tratada con absoluto respeto a sus condiciones físicas. El "churriguerismo ha inventado estas formas panzudas que no responden a la comodidad ni a la belleza, y solo sirven para recargar de material los objetos, o dejar la solidez falsa vetisegando la madera" ${ }^{14}$. La decoración de tornería, talla, marquetería o barnices - un repertorio muy decimonónico- ha de poner de relieve las

Rigalt, L., Album, págs. 16 y ss.

Rigalt, L., op. Cit, sección "Carpinteria", sin paginación

14 Rigalt, L., op. Cit, sección "Carpintería», sin paginación. 

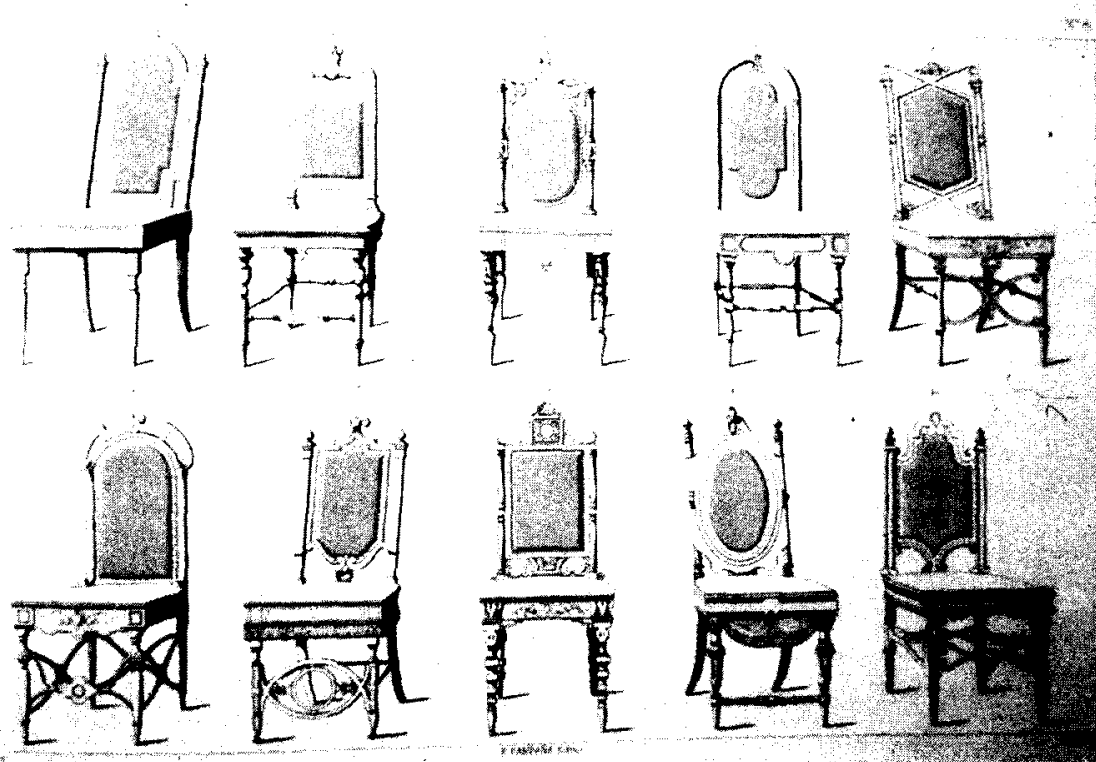

Figura 3. RIGALT, Album. Sillas de formas aptas para ser tomadas como modelo por los fabricantes de muebles.

cualidades de la veta y el color de la madera. Se rechazan los excesos de talla, los coloreados caprichosos, los capeados que oculten una carcasa defectuosa, y las molduras, resaltes y perfiles que rompan con la unidad de un miembro componente.

El repertorio tipológico que Rigalt presenta se reduce, en la búsqueda de la simplicidad que preside sus trabajos, a los muebles básicos para satisfacer las necesidades de la vida - de la vida burguesa de mediano pasar- prescindiendo de los de ostentación y capricho: lechos, muebles de asiento, armarios, cómodas, mesas, escritorios, tocadores, tremós. La terminología escogida para denominar cada mueble revela una clara voluntad de desterrar los galicismos al uso, sustituyendo, por ejemplo, el habitual "secreter" por "papelera" o "toilette" por "tocador», y de recuperar términos olvidados del vocabulario español, como «ataifor», que aplica a la mesa de centro ${ }^{15}$.

${ }_{15}$ El ataifor es una mesa que sirve al mismo tiempo como plato, baja y redonda, originaria del mundo musulmán, que en España siguió siendo utilizada por los moriscos. Aunque Nebrija lo identifique como un aparador, Covarrubias fundamenta la primera descripción. 


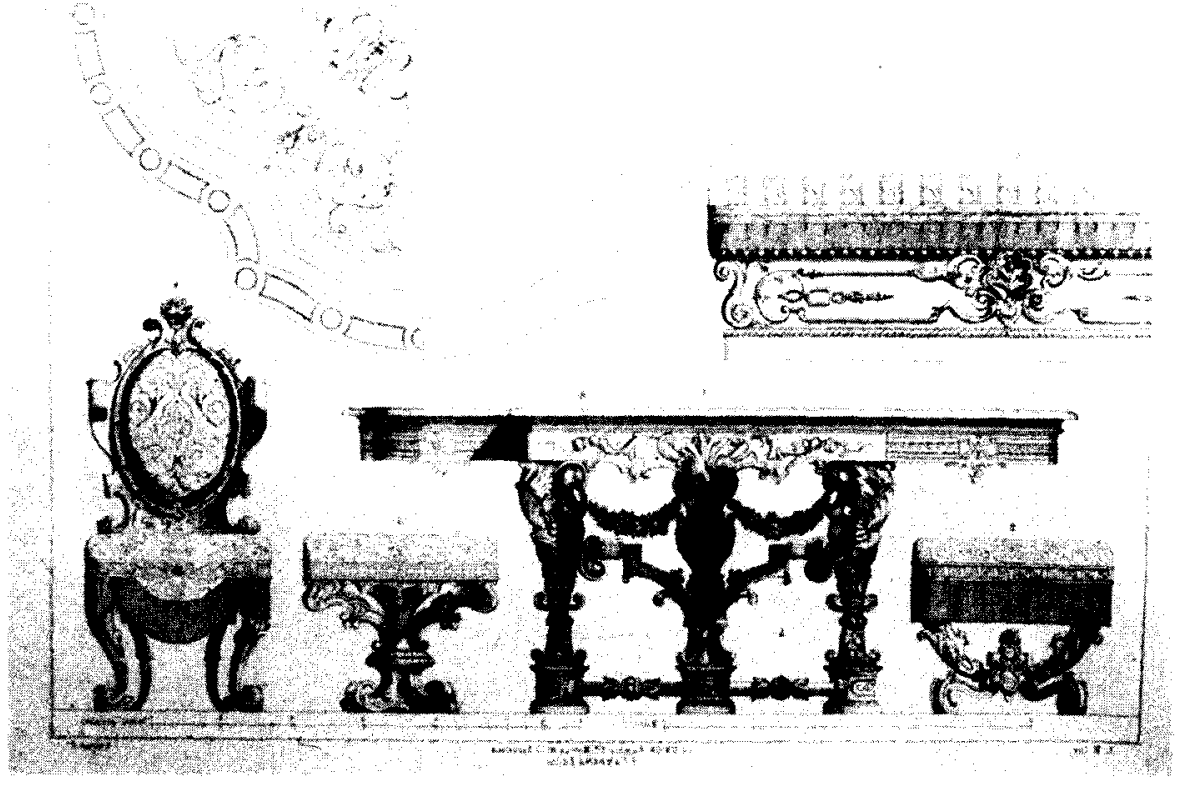

Figura 4. RIGALT, Album. Ataifor, taburetes, silla de salón y diván u otomana. "Extravagancias churriguerescas".
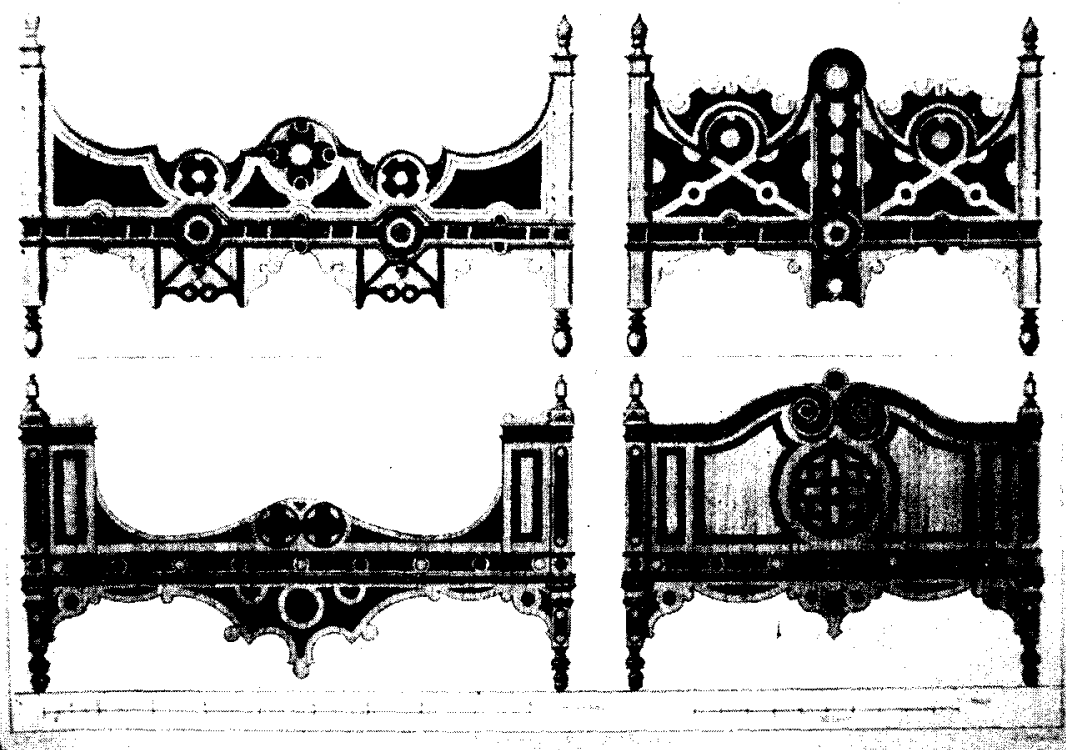

Figura 5. RIGALT, Album. Camas de sofá, llamdas "a la francesa". Ejemplo de formas faltas de solidez, ya que requieren el vetisegado de la madera. 
Del martillo y el escoplo a la máquina de machihembrar. La industria del mueble...

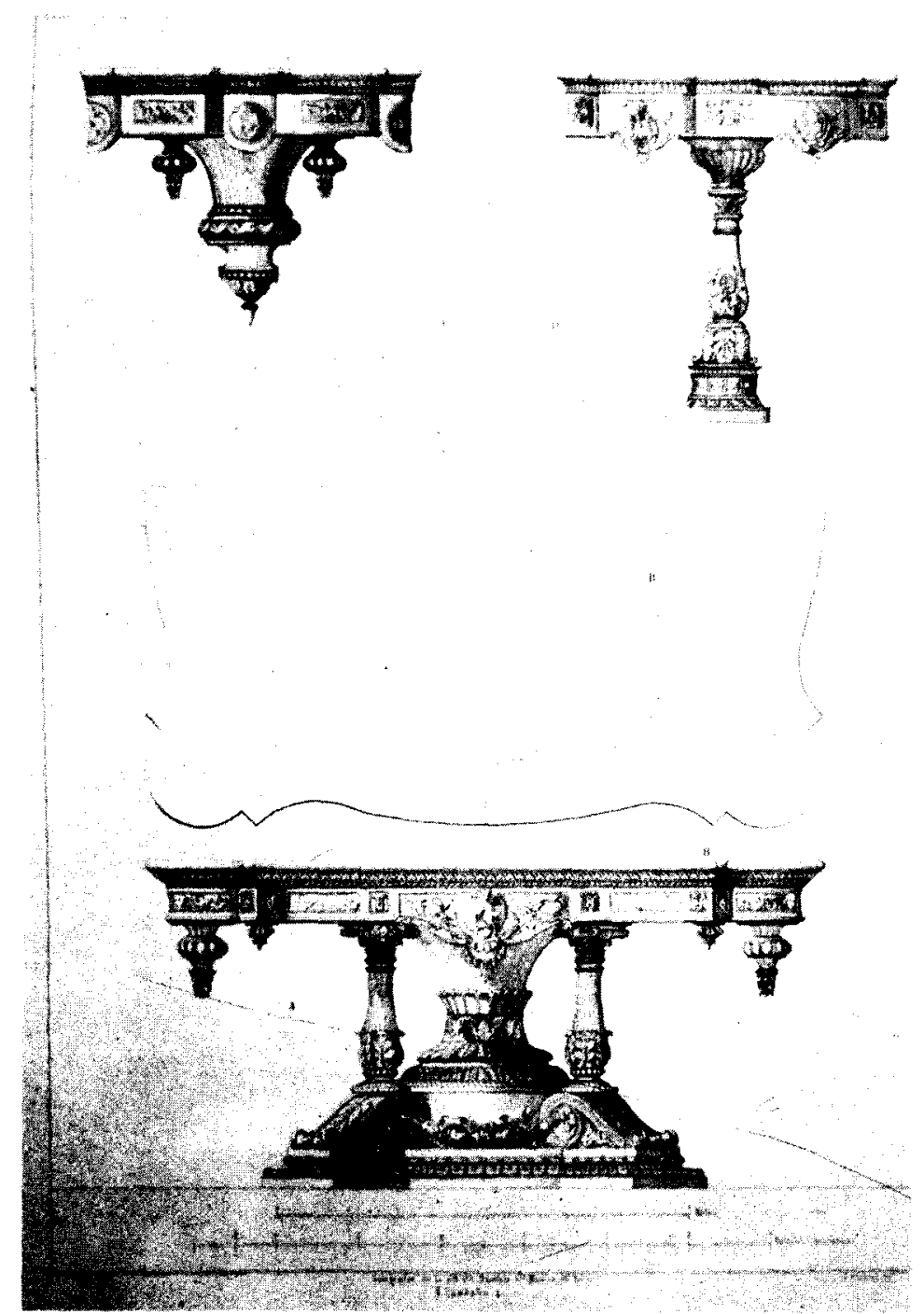

Figura 6. RIGALT, Album. Mesa-ataifor para sala de grandes dimensiones. Estilo "plateresco o del Renacimiento». 
Rigalt se inscribe en un ambiente general que, durante la segunda mitad del siglo XIX, produce una literatura modesta, pero no desdeñable, sobre las artes industriales, consistente en manuales teórico-prácticos, publicaciones periódicas especializadas y estudios de carácter histórico y erudito, todos ellos propagadores de las nuevas ideas que habian de fomentar el desarrollo de las artes industriales españolas.

La vertiente pedagógica está representada por textos destinados a la formación de trabajadores que tratan de adaptarse al reto de los talleres modernos, aunque con frecuencia pequen de un excesivo paternalismo. Nicolás de Bustinduy, en un artículo aparecido en La semana industrial, en el que da instrucciones para la redacción de este género de textos, advierte que es aconsejable que se haga hincapié en «aquella parte de la ciencia que tuviera inmediata aplicación al taller, y desarrollada con la claridad y concisión necesarias para su corta inteligencia (la de los obreros)" " ${ }^{16}$. Al hilo de las necesidades de las escuelas de formación profesional van surgiendo tratados de perspectiva, geometría y otras disciplinas básicas para acercar

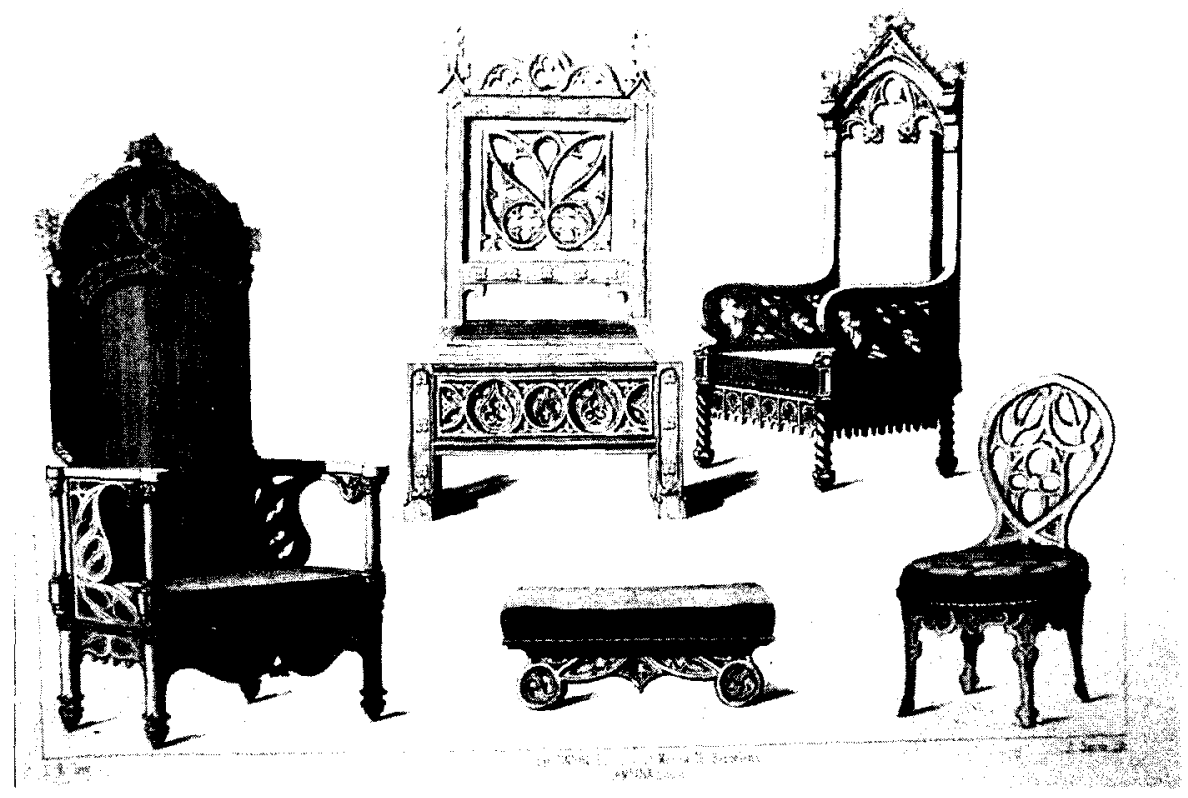

Figura 7. RIGALT, Album. Sillas y sillones de respeto "góticos".

16 Bustinduy, Nicolás de, "Escuela de Artes y Oficios de San Sebastián", La semana industrial, 1884, III. 

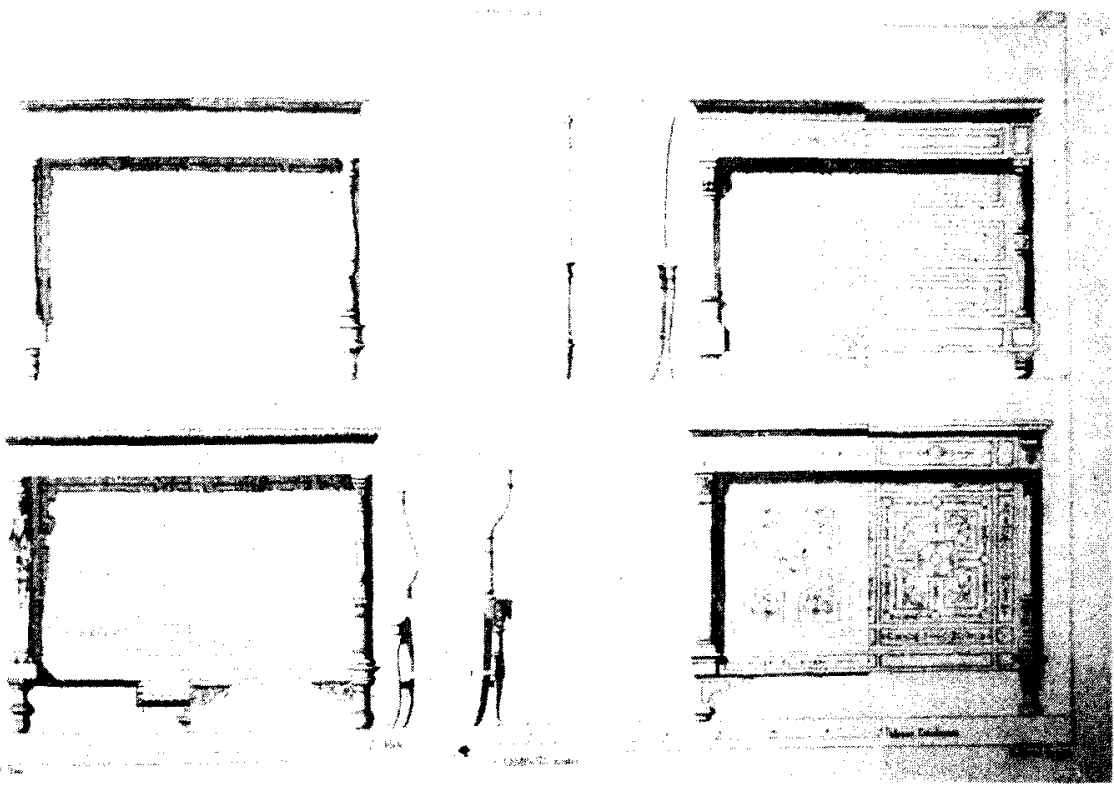

Figura 8. RIGALT, Album. Comodas y sillas demadera sólida, adecuadas a la fabricación industrial.

a los alumnos al estudio de la forma, manuales sobre la madera, los ensamblajes y la ornamentación, y otros escritos de semejante carácter ${ }^{17}$.

Las publicaciones periódicas especializadas están destinadas a los profesionales y aficionados, a los que tratan de familiarizar con las modas europeas, en general sin criterios selectivos, o con el solo criterio de la pura novedad, a través de artículos y de ilustraciones detalladas y profusas, que a menudo sirvieron asímismo como modelos de taller. La más importante es El museo de la industria, de corta vida (1870-73), en cuyos apéndices figuraban láminas a gran escala de alzados y plantas de muebles y objetos de consumo. Muebles ingleses de la tradición dieciochesca conviven con pastiches franceses, con rústicos muebles de madera vista alemanes y, sin que merezcan un comentario diferenciador por lo que suponen de ruptura, con

Cabe citar a A. Y C. CASTELUCHO, Director de la Escuela oficial de Bellas Artes de Barcelona, Tratado completo de perspectiva aplicada a las Bellas Artes y Artes industriales, Barcelona, h. " 1893; a Eugenio PLA y RAVE, "Manual del maderero", vol. 52 de la Biblioteca enciclopédica popular ilustrada, Madrid, 1882; a Gabriel GıRONI y a sus publicaciones Las pequeñas industrias domésticas, Madrid, 1881, Enseñanza industrial, Madrid, 1885, y Lo que deben ser las escuelas de Artes y Oficios, con los programas para su enseñanza, Madrid, 1893. 


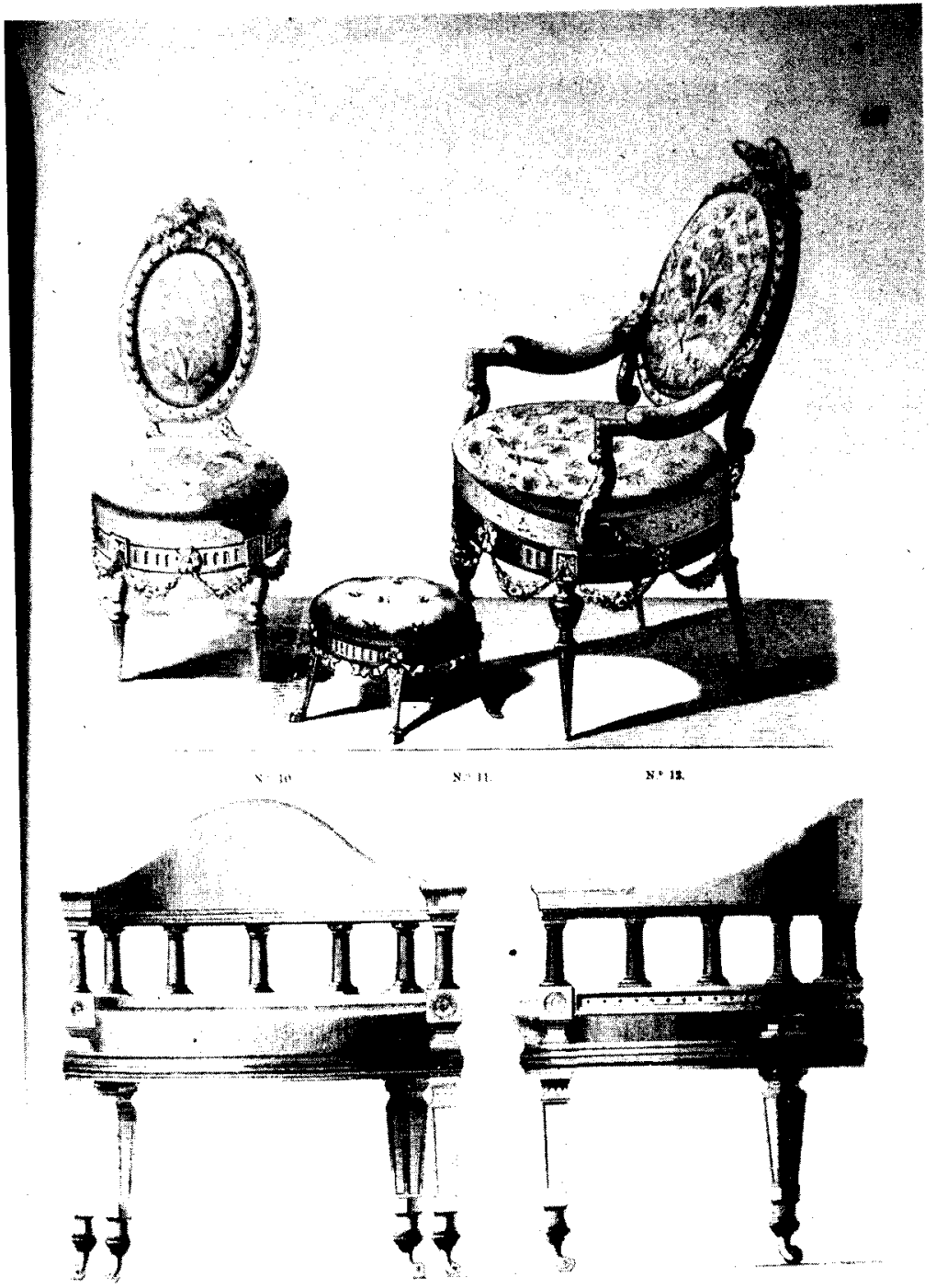

Figura 9. El Museo de la Industria, 1870-71. 
alguno de los productos diseñados por la empresa Morris \& C. . En las revistas para ingenieros e industriales también se dedica amplio espacio a las artes industriales y a la mecanización de los talleres, a propósito de la búsqueda de vías para la mejora de las infraestructuras y para la reactivación de la economia nacional. Cabe mencionar los esfuerzos que se hicieron desde La semana industrial, en la que el ingeniero Gumersindo Vicuña llevó la voz cantante en la defensa de la modernización del país, La gaceta industrial, económica y científica (aparecida en 1867) y los Anales de la construcción y de la industria (que vió la luz en 1878).

Los estudios históricos contribuyeron a orientar la búsqueda de nuevos modelos formales hacia la tradición histórica española, al procurar imágenes de de tipologías y ornamentaciones del pasado, datadas y documentadas, aunque con las imprecisiones propias de la época. Se puede decir que la historia del mobiliario histórico arranca en nuestro país en la década de los setenta, con las aportaciones de Juan Facundo Riaño y su catálogo de objetos hispánicos de la colección del South Kensington Museum ${ }^{18}$, y de Miquel y Badía ${ }^{19}$. Este último, por ejemplo, en sus Cartas a una señorita sobre la habitación ${ }^{20}$ incluye reproducciones de estancias medievales procedentes del Dictionnaire raisonné du mobilier français ${ }^{21}$, y un amplio muestrario de objetos españoles o considerados entonces como tales ${ }^{22}$.

España también quiso crear sus propios museos de artes industriales, que proliferan en Europa con una finalidad pedagógica que va más allá de la mera exhibición de objetos para la contemplación, y que está relacionada con el desarrollo de las industrias nacionales, para las que proponen sus colecciones como ejemplos de inspiración. Durante el reinado de Amadeo 1 se intentó crear en Madrid un Museo de Artes Industriales, que no prosperó.

Todas estas iniciativas están impregnadas de un idealismo nacionalista que sublima el pasado a través de la reconstrucción frecuentemente poco precisa de sus producciones artísticas y artesanales, y que pretende

18 Riaño, Juan Facundo, Classified and Descriptive Catalogue of the Art Objects of Spanish Production in the South Kensington Museum, Londres, 1872.

${ }_{14}$ F. MIQUel I BADIA es el primer autor que publica un estudio sistemático y documentado sobre la historia del mueble en el vol. VIII de Historia General del Arte, Barcelona, 1897, titulado "Muebles, tejidos, metalisteria y cerámica".

¿MIQUel I BADIA, F., Muebles y tapices. Segunda serie de cartas para una señorita sobre la habitación, Barcelona, 1879

VIOLLET-LE-DUC, E.E., Dictionnaire raisonné du mobilier français de l'époque Carolingienne à la Rennaissance, vol. I, Paris, 1858.

22 Por ejemplo, un stipo genovés de principios del siglo XVII se cataloga como "Carlos $V$ " y español, error que se ha repetido prácticamente hasta la actualidad en la bibliografia española sobre mobiliario. 
ser al tiempo motor del presente. En suma, un ropaje vernáculo con el que vestir el progreso industrial y dotarlo de raíces.

Los talleres e industrias acaban por aprovechar los materiales que se ponen a su disposición. Los dibujos de objetos artísticos se emplearán sistemáticamente en las fábricas y talleres durante los últimos veinte años del siglo, no solo para proporcionar modelos con qué trabajar a los operarios, sino también catálogos a la clientela para orientar sus encargos. La figura del «director artístico» toma carta de naturaleza, y se encarga de diseñar los muebles de creación propia y de seleccionar los que se han de copiar, con o sin variantes, de los repertorios extranjeros. La oferta que resulta es amplia y acomodaticia: ninguno de los industriales españoles se decanta con claridad hacia propuestas europeas renovadoras. Las imitaciones se anuncian sin ambages: Segundo Santa Bárbara, por ejemplo, presenta en la Exposición Nacional de 1898 un mueble ideado por personal de su firma y otro copiado de uno francés. Entre los catálogos de la firma Apolinar coexisten «renacimientos" españoles con muebles de estilo francés e inglés y con con robustos conjuntos alemanes; de estos, se conserva un grupo de ejemplares de una publicación germánica junto a las copias casi literales dibujadas por el director artístico.

A fin de siglo es ya de buen tono hacer constar que las tiendas de decoración cuentan con catálogos ilustrados. Por ejemplo, en el popular anuario Bailly-Baillière se anuncian destacando este servicio, en 1897, dos famosas fábricas, $L$. de Armentia, de Vitoria, y Vallejo, de Madrid.

\section{LA FORMACIÓN DE LOS TRABAJADORES Y LA ORGANIZACIÓN DEL TRABAJO}

La decisión de las Cortes Generales de poner fín a la organización gremial en 1836, al permitir el libre ejercicio de las industrias provocó, a pesar de su buena intención, la desorganización de la práctica artesanal y el fín de las garantías de calidad, debido al vacio que se produjo en la enseñanza de los oficios. La obligatoriedad de alcanzar la maestría no se vió compensada inmediatamente por un sistema pedagógico alternativo, que ni el Conservatorio de las Artes de Madrid, ni las iniciativas particulares de filántropos que fundaban cátedras de geometría y química aplicadas fueron capaces de desarrollar.

La formación de industriales y artesanos bien preparados para la libre práctica de las profesiones fué preocupación constante durante toda la centuria. La paulatina mecanización y el surgimiento de nuevas pautas forma- 


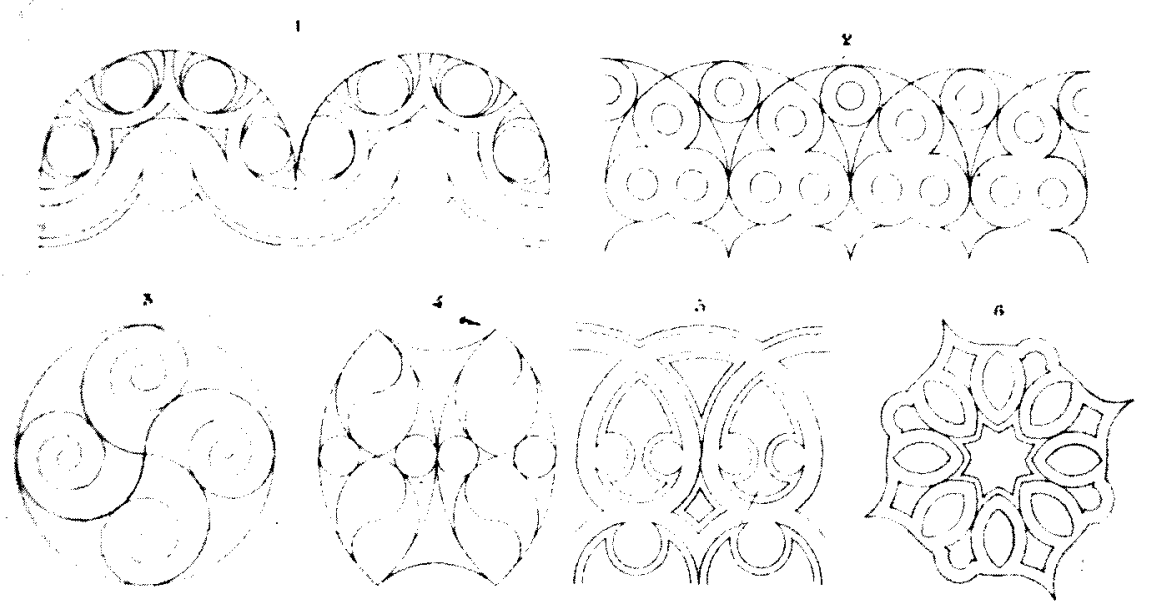

Figura 10. RIGALT, Cartapacios gráficos de dibujo y geometria (sin fecha). Ejercicios de trazado geométrico y de formas sencillas de objetos para alumnos de las escuelas de artes $y$ oficios.

les encauzaron los programas didácticos hacia la integración de la teoria y la técnica; la írase pronunciada por el Director de la Escuela de Artes y Oficios de Barcelona en la apertura del curso 1882-83, "ni teoría sin práctica, ni práctica sin teoría" ${ }^{23}$ inspira los planes de estudios de todos los centros de educación públicos y privados. $Y$ es que, en palabras de Rigalt, «la destreza no basta...Pongamos, por ejemplo, un carpintero. Ensáyase el principiante en manejar cepillo y sierra; aprieta tornillos, ajusta tablas, bruñe maderas. Más adelante empieza a cortar piezas sobre medidas dadas, a labrar embutidos según moldes, a abrir calados siguiendo un dibujo. Esto lleva algunos años de aprendiz y de oficial hasta que, adquirida destreza, puede ganar diez o doce reales diarios" ${ }^{24}$. Más allá de esta pobre práctica artesanal está la capacitación de nuevos profesionales, desde el obrero al jefe de taller, pasando por el oficial. El que más reclama la atención de los pedagogos es el segundo, al que atañen responsabilidades que rebasan las de los antiguos maestros: no solo es imprescindible que conozca las propiedades de los materiales y el uso de las herramientas adecuadas a su

\footnotetext{
${ }^{23}$ La semana industrial, noviembre 1882, recensión del discurso; el texto completo se publicó en El porvenir de la industria, 13 de octubre de 1882.

${ }^{24}$ Rigalt, op. cit, pág. 7.
} 


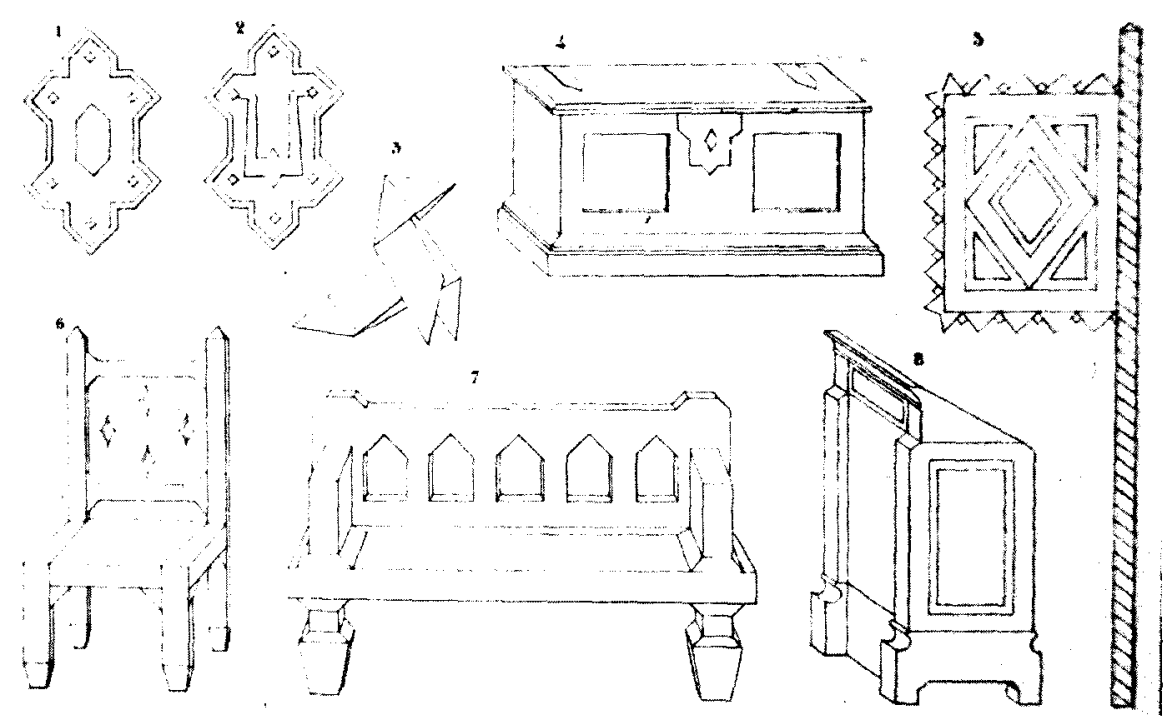

Figura 11. RIGALT, Cartapacios gráficos de dibujo y geometria (sin fecha). Ejercicios de trazado geométrico y de formas sencillas de objetos para alumnos de las escuelas de artes y oficios.

naturaleza, sino también el dominio de la geometría aplicada al diseño y, 10 que es más importante, la capacidad de crear ideas y formas que definan cada uno de los objetos a fabricar. A fin de siglo el director artístico se añade a la plantilla de los grandes establecimientos.

La enseñanza profesional se imparte en las Escuelas de Artes y Oficios y en centros patrocinados por organismos y asociaciones varias que promueven, con más o menos éxito, actividades aisladas. En todos los casos las materias de estudio se estructuran de manera común. La instrucción teórica comprende por un lado la aritmética y la geometría, para iniciar al alumno en el conocimiento de las formas básicas, y por otro el dibujo, tanto para que lo domine y le auxilie en la concepción de objetos, como para que, a través de su ejercicio, pueda aprender, copiando modelos del pasado, algo acerca de la historia de las artes decorativas que le ofrezca fuentes futuras de inspiración. Copias de adornos, de arquitecturas y de objetos de diferentes estilos se realizan en las aulas sobre modelos del natural, vaciados en escayola de obras notables y maquetas. El adiestramiento manual tiene lugar en talleres donde se experimenta con un conjunto de útiles, materiales y máquinas cuya variedad depende de los recursos de las escuelas. El deseo generalizado, no siempre logrado, es que las instalaciones se completen con un archivo, una biblioteca y un pequeño museo industrial y artís- 
tico ${ }^{25}$. Este sistema educativo procede de Francia, donde nació para llenar el vacio dejado por la supresión del sistema gremial anterior a la Revolución.

El Conservatorio de las Artes de Madrid, nacido en 1824, es el primer organismo oficial que aplica las novedades pedagógicas. Estaba organizado en cátedras de materias que, en palabras de Mesonero Romanos, debían impartir "los conocimientos de la geometría, mecánica, física y química que puedan servir para mejorar las arłes y fábricas" ${ }^{25}$. El Conservatorio se constituyó, asímismo, en depósito de los modelos presentados con las solicitudes de privilegios, más tarde denominados patentes, que debían integrarse en un museo multidisciplinar. Este comprendería, además, un gabinete de historia natural y de física, un laboratorio de química, un muestrario de materias primas y otro de herramientas y maquinaria. La desidia y la falta de medios malograron este ambicioso proyecto. El Conservatorio pervivió con altibajos, intenciones permanentes de reforma y cambios de rumbo, y sobre sus directores planeó siempre la tentación de transformarlo en una "bellísima Academia de Bellas Artes", como comenta sarcásticamente el ingeniero Gironi ${ }^{26}$. Esta institución acabó por convertirse en la Escuela de Artes y Oficios de Madrid.

Diputaciones, ayuntamientos, juntas de comercio y sociedades de amigos del país fueron creando otras escuelas de Artes y Oficios en Béjar, Avilés, Barcelona, Bilbao, Cádiz, Gijón, Logroño, Salamanca, Santander, San Sebastián, Sevilla, Valencia, Valladolid y Zamora. Las asociaciones de iniciativa particular, como ateneos y agrupaciones patronales y gremiales impartieron cursos y conferencias, convocaron concursos y organizaron exposiciones, en unos casos como alternativa a la enseñanza oficial, y en otros para poner al día los conocimientos de los trabajadores en ejercicio. En Madrid, el Fomento de las Artes, nacido de una asociación Ilamada "La velada", llegó a contar en sus aulas, en 1885, con seis mil obreros, y produjo exposiciones de artes decorativas con regularidad desde 1884. En Barcelona la actividad particular fué más extensa, y se fundaron más centros de estudios que en el resto de la Península. Los más importantes fueron el Instituto de la industria catalana (1848), el Centre instructiu del ram de l'ebenisteria, que daba clases nocturnas y conferencias, el/nstitut català d'artesans del obispo Lluch i Garriga, que tejió una tupida red de centros por Cataluña y, sobre todo, el Foment del traball nacional, impulsado por patronos progresistas, responsable de las exposiciones de artes decorativas para su aplicación a la industria de 1880 y 1884.

Mesonero Romanos, R., op. cit., pág. 210.

GiRoni, G., "El Conservatorio de las Artes», La semana industrial, 1884, pág. 
